\title{
Ibuprofen increases the serum Omentin levels in rats after abdominal surgery
}

1. Associate Professor, Abant Izzet Baysal University Hospital, Department of General Surgery, Bolu, Turkey 2. Associate Professor, Abant Izzet Baysal University Hospital, Department of Internal Medicine, Bolu, Turkey 3. Assistant Professor, Abant Izzet Baysal University Hospital, Department of General Surgery, Bolu, Turkey 4. Assistant Professor, Abant Izzet Baysal University Hospital, Department of General Surgery, Bolu, Turkey

\section{SUMMARY}

AIMS: Omentin is an adipokine primarily produced by visceral adipose tissue and its reduced levels have been shown to be associate with worse metabolic outcomes. We aimed to study the effects of preoperative ibuprofen on postoperative omentin levels in rats after surgery. METHODS: Forty-eight albino Wistar rats, 6 in each of 8 groups according to the surgical procedure (laparotomy, laparotomy plus ibuprofen (IBU), nephrectomy, nephrectomy plus IBU, hepatectomy, hepatectomy plus IBU, splenectomy and splenectomy plus IBU). The Omentin levels of the groups were postoperatively analyzed.

RESULTS: The mean omentin was significantly higher in the laparotomy plus IBU group compared to the laparotomy group ( $p<0.001)$. Mean Omentin was significantly higher in the hepatectomy plus IBU group compared to the hepatectomy group ( $p=0.01)$. Mean Omentin was significantly higher in the nephrectomy plus IBU group compared to the nephrectomy group $(p=0.001)$.

CONCLUSION: We suggest that preoperative ibuprofen may enhance circulating levels of Omentin, which has beneficial effects in trauma and inflammation settings in subjects that undergo minor or major abdominal surgery.

KEYWORDS: Ibuprofen. Adipokines. Rats, Wistar. Surgical procedures, operative. Abdomen/surgery.

\section{INTRODUCTION}

The main purpose of body functions after trauma is maintaining hemostasis by developing systemic and local responses against trauma. The neuroendocrine response to trauma, release of mediators, intracellular and intercellular metabolic changes vary according to the time and type of the trauma. Regardless of the size, surgery is trauma and promotes a chain reaction in the body that causes various metabolic endocrine responses.
The central nervous system plays an important role in the regulation of the inflammatory response. Traditionally, the autonomic nervous system regulates the heart rate, blood pressure, respiration rate, gastrointestinal motility, and body temperature. Specific sites of inflammation send afferent signals to the hypothalamus. As a result, anti-inflammatory messages quickly swing to reduce inflammatory mediators ${ }^{1}$.

The central nervous system responds to 
immunological signals via circulation and the neural pathways. Although the blood-brain barrier blocks many substances, it allows the passage of inflammatory factors, such as tumor necrosis factor (TNF). Symptoms including fever, anorexia, and depression occur by the humoral pathway of inflammatory signals. Cytokines, baroreceptors, chemoreceptors, and thermoreceptors carry afferent stimulus to the vagal nerve from the site of trauma. Vagal stimulation decreases heart rate, increases intestinal motility, dilates the arterioles, constricts the pupil, and regulates inflammation.

Cytokines, especially TNF and interleukin-1 (IL-1) are known to have effects on energy metabolism and appetite. It is demonstrated in many studies that these effects of cytokines were associated with adipokines ${ }^{2}$.

Omentin is a $34 \mathrm{kDa}$ new adipokine primarily produced by visceral adipose tissue. Decreased omentin levels have been shown to be associated with worse metabolic outcomes in diabetic patients ${ }^{3}$.

Cytokines are known to increase after operations or injury. Ibuprofen (IBU) prevents the production of proinflammatory prostaglandins by inhibiting cyclooxygenase 1 and 2. It is thought that ibuprofen improves appetite by the same way ${ }^{4}$.

Although it has been shown in the literature that several adipokines were associated with appetite affected by surgery and ibuprofen treatment, to our knowledge, there is no report about omentin in this regard. Observing omentin levels in rats after surgery may provide useful clinical information due to the potentially common pathogenesis. Therefore, we aimed to study the effects of preoperative ibuprofen on postoperative omentin levels in rats after surgery.

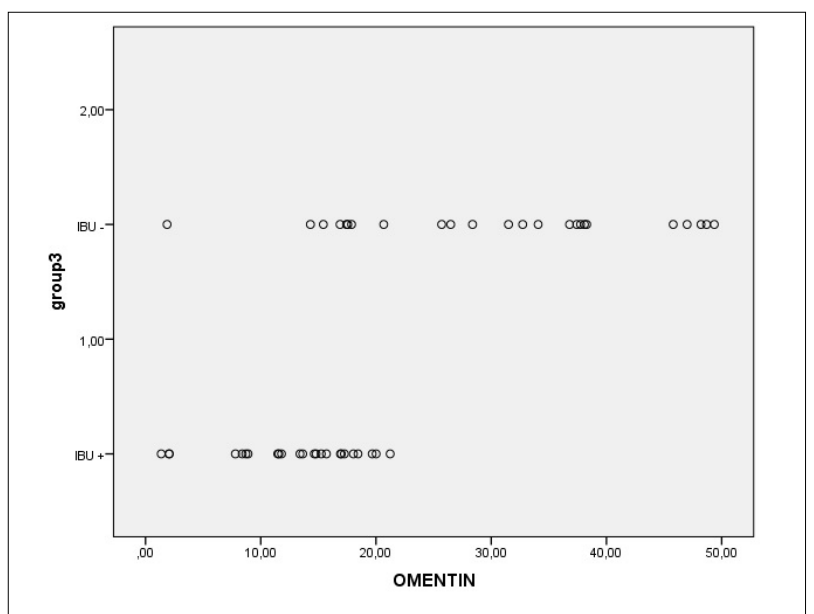

\section{METHODS}

Forty-eight Wistar albino rats (6 rats in each group) were included in the study. Study groups were as follows: laparotomy (L); laparotomy + IBU (LI); hepatectomy (H); hepatectomy + IBU (HI); nephrectomy (N); nephrectomy + IBU (NI); splenectomy (S); and splenectomy + IBU (SI). The rats in LI, HI, NI, and SI groups were weighed 18 hours before surgery, and $30 \mathrm{mg} / \mathrm{kg}$ of ibuprofen was administered via gastric tube. Retro-orbital blood samples were obtained from the rats 18 hours after surgery. The same surgeons performed surgical interventions under general anesthesia with an intramuscular injection of $50 \mathrm{mg} / \mathrm{kg}$ of Ketamine (Ketalar $50 \mathrm{mg} / \mathrm{ml}$, Eczacıbaşı, İstanbul) and $5 \mathrm{mg} / \mathrm{kg}$ of Xylazine (Rompun $20 \mathrm{mg} / \mathrm{ml}$, Bayer, İstanbul). After disinfection, a $3 \mathrm{~cm}$ median incision was done on all rats. After the incision, partial hepatectomy, splenectomy, or unilateral nephrectomy was performed and the skin sutured with 000 silk sutures after hemostasis. Postoperatively, $3 \mathrm{ml}$ of blood samples were obtained from the abdominal aorta under general anesthesia, after the experimental protocol finished.

The omentin levels were assessed from postoperative blood samples. Venous blood samples were centrifuged for ten minutes at 1000 rpm for separation of the serum. Omentin in these sera was studied by sandwich ELISA kits of Biovendor (Brno, Czech Republic) according to the manufacturer's instructions.

Data was analyzed with SPSS software (SPSS 15.0 for Windows, IBM Co., Chicago, Il, USA). Independent samples t-test was used in the comparison of omentin between the study groups. Data were expressed as mean \pm standard deviation. A p-value $<0.05$ considered as statistically significant.

TABLE 1. OMENTIN LEVELS OF THE STUDY GROUPS

\begin{tabular}{l|l|l} 
Groups & Omentin $(\mathrm{ng} / \mathrm{mL})$ & $P$ \\
\cline { 1 - 2 }$L(n=6)$ & $8.8 \pm 5.7$ & $<0.001$ \\
\cline { 1 - 1 }$(n=6)$ & $34.9 \pm 10$ & \\
\hline$H(n=6)$ & $13.9 \pm 3.5$ & 0.01 \\
\cline { 1 - 1 }$(n=6)$ & $31.8 \pm 14.4$ & 0.001 \\
\cline { 1 - 2 }$(n=6)$ & $14.9 \pm 4$ & \\
\cline { 1 - 2 }$(n=6)$ & $34 \pm 9.5$ & 0.37 \\
\cline { 1 - 2 }$(n=6)$ & $14.1 \pm 7.9$ & \\
\hline$S I(n=6)$ & $20.7 \pm 15.1$ &
\end{tabular}




\section{RESULTS}

There were 6 rats in each of the L, LI, H, HI, N, NI, $\mathrm{S}$, and SI groups. The mean omentin levels of the $\mathrm{L}$ and LI groups were $8.8 \pm 5.7 \mathrm{ng} / \mathrm{mL}$ and $34.9 \pm 10 \mathrm{ng} /$ $\mathrm{mL}$, respectively $(\mathrm{p}<0.001)$. The mean omentin levels of the $\mathrm{H}$ and $\mathrm{HI}$ groups were $13.9 \pm 3.5 \mathrm{ng} / \mathrm{mL}$ and 31.8 $\pm 14.4 \mathrm{ng} / \mathrm{mL}$, respectively $(\mathrm{p}=0.01)$.

The mean omentin levels of the $\mathrm{N}$ and NI groups were $14.9 \pm 4 \mathrm{ng} / \mathrm{mL}$ and $34 \pm 9.5 \mathrm{ng} / \mathrm{mL}$, respectively $(\mathrm{p}=0.001)$. The mean omentin levels of the S and SI groups were $14.1 \pm 7.9 \mathrm{ng} / \mathrm{mL}$ and $20.7 \pm 15.1 \mathrm{ng} / \mathrm{mL}$, respectively $(p=0.37)$. Table 1 shows the omentin levels of the study population. Figure 1 shows the omentin levels of the subjects received or not received ibuprofen.

\section{DISCUSSION}

The main discovery of the present study is that the preoperative administration of ibuprofen increases the serum levels of Omentin in rats that undergo minor and major surgery, which may be beneficial in the treatment of subjects after a surgical procedure.

Omentin is an adipokine that is produced in visceral adipose tissue ${ }^{5}$. Recent data support that it has a crucial role in the regulation of inflammation. Decreased levels of omentin in synovia have been reported in rheumatoid arthritis ${ }^{6}$, and reduced omentin messenger RNA expression has been reported in the omentum of subjects with Chrohn's disease ${ }^{7}$. Authors reported reduced omentin levels in acute appendicitis $^{8}$ and mesenteric ischemia settings ${ }^{9}$. On the other hand, the effects of C-reactive protein and tumor necrosis factor-alpha on endothelial cells were reduced by omentin ${ }^{10}$. These reports suggest that omentin is an anti-inflammatory cytokine.

Authors have reported elevated omentin in neoplastic disease. Increased omentin has been reported in subjects with prostate cancer ${ }^{11}$. The elevation of adipokine in cancer could be a defense mechanism of the body since it induces apoptosis in tumor cells ${ }^{12}$.

Omentin is also associated with conditions that are characterized by low burden inflammation. For instance, the omentin receptor gene in adipose tissue is down-regulated in obese subjects ${ }^{4}$. As a result, serum omentin decreases in obesity. Body mass index, serum leptin, and waist circumference, the markers of obesity, are inversely correlated with circulating omentin levels ${ }^{13}$. Current literature not only suggests that omentin is lower in obese subjects, but also that weight reduction promotes elevation in circulating omentin levels ${ }^{14}$. Serum omentin levels are also decreased in subjects with type 2 diabetes mellitus, another low inflammatory condition ${ }^{15}$. Omentin levels in patients with polycystic ovary syndrome are reported to be reduced ${ }^{16}$. Polycystic ovary syndrome is also associated with obesity, insulin resistance, and low-grade inflammation.

Reduced omentin has been reported in other clinical conditions too. Omentin was significantly decreased in pregnant women compared to non-pregnant age-matched controls ${ }^{17}$. Tekce et al. ${ }^{18}$ reported that omentin levels decreased in patients with chronic kidney disease. Indeed, laparotomy, hepatectomy, and nephrectomy all cause a significant amount of inflammation, which could reduce the circulating omentin levels. Anti-inflammatory agents may not only reduce inflammation but also increase omentin and thus have beneficial effects after surgery. Ibuprofen is a non-steroidal anti-inflammatory drug. It inhibits the synthesis of prostaglandins from the Arachidonic acid pathway. Our data suggest that omentin may also mediate the anti-inflammatory properties of ibuprofen.

Limitations of the present study are the lack of measurement of other inflammatory markers, such as C-reactive protein. Another limitation could be the low number of test subjects in each study group. However, the results of the present study indicating the importance of ibuprofen administration on omentin levels are very important.

In conclusion, we suggest that preoperative ibuprofen may enhance circulating levels of omentin, which has beneficial effects in a trauma and inflammation setting, in subjects that undergo minor or major abdominal surgery. Prospective studies about the effects of omentin and preoperative ibuprofen on surgical complications, length of hospital stay, and related factors are needed.

\section{$\mathrm{COI}$ statement and funding statement}

The authors have no conflict of interest. This work has not received any funds or grants from any organizations.

\section{Author's Contributions}

MS, BO, and OC designed the study. MS and OC performed the literature search. MS and BO performed surgical procedures. BO, OC, GA performed the statistical analyses. GA and MS wrote the manuscript. BO and OC performed the critical review of the first draft 


\section{RESUMO}

OBJETIVOS: A omentina é uma adipocina produzida principalmente pelo tecido adiposo visceral e níveis reduzidos dela foram associados a piores desfechos metabólicos. Nosso objetivo foi estudar os efeitos do uso pré-operatório do ibuprofeno nos níveis pós-operatórios da omentina em ratos.

METODOLOGIA: Quarenta e oito ratos Wistar albinos foram divididos em 8 grupos (6 em cada), de acordo com o procedimento cirúrgico: laparotomia, laparotomia e ibuprofeno (IBU), nefrectomia, nefrectomia e IBU, hepatectomia, hepatectomia e IBU, esplenectomia, e esplenectomia e IBU. Os níveis de omentina dos grupos foram analisados após a cirurgia.

RESULTADOS: A omentina média foi significativamente maior no grupo de laparotomia e IBU do que no grupo de laparotomia ( $p<0,001)$. A omentina média foi significativamente maior no grupo de hepatectomia e IBU do que no grupo de hepatectomia $(p=0,01)$. A omentina média foi significativamente maior no grupo de nefrectomia e IBU do que no grupo de nefrectomia $(p=0,001)$.

CONCLUSÃo: Sugerimos que o uso pré-operatório de ibuprofeno pode aumentar os níveis circulantes de omentina, que têm efeitos benéficos em um contexto de trauma e inflamação em indivíduos submetidos cirurgia abdominal.

PALAVRAS-CHAVE: Ibuprofeno. Adipocinas. Ratos, Wistar. Procedimentos cirúrgicos, operatórios. Abdome/cirurgia.

\section{REFERENCES}

1. Wang Z, Nakayama T. Inflammation, a link between obesity and cardiovascular disease. Mediators Inflamm. 2010;2010:535918.

2. Zivna H, Zivny $P$, Palicka V. Serum leptin concentrations after surgery in young rats. Nutrition. 2002;18(7-8):643-6.

3. Yoo HJ, Hwang SY, Hong HC, Choi HY, Yang SI, Seo |A, et al. Association of circulating omentin-1 level with arterial stiffness and carotid plaque in type 2 diabetes. Cardiovasc Diabetol. 2011;10:103.

4. Tan BK, Adya R, Randeva HS. Omentin: a novel link between inflammation, diabesity, and cardiovascular disease. Trends Cardiovasc Med. 2010;20(5):143-8.

5. Yang RZ, Lee MJ, Hu H, Pray J, Wu HB, Hansen BC, et al. Identification of omentin as a novel depot-specific adipokine in human adipose tissue: possible role in modulating insulin action. Am | Physiol Endocrinol Metab. 2006;290(6):E1253-61.

6. Senolt L, Polanská M, Filková M, Cerezo LA, Pavelka K, Gay S, et al. Vaspin and omentin: new adipokines differentially regulated at the site of inflammation in rheumatoid arthritis. Ann Rheum Dis. 2010;69(7):1410-1.

7. Schäffler A, Neumeier M, Herfarth H, Fürst A, Schölmerich J, Büchler C. Genomic structure of human omentin, a new adipocytokine expressed in omental adipose tissue. Biochim Biophys Acta. 2005;1732(1-3):96-102.

8. Sit M, Catal O, Aktas G, Yilmaz EE, Tosun M, Savli H. Serum amyloid A and Omentin levels in acute appendicitis: a preliminary study for a novel diagnostic approach. Clin Ter. 2014;165(1):e35-8.

9. Sit M, Aktas G, Yilmaz EE, Tosun M, Terzi EH, Alcelik A. Serum omentin levels predicts mesenteric ischemia. Bratisl Lek Listy. 2015;116(3):173-6.

10. Tan BK, Adya R, Farhatullah S, Chen J, Lehnert H, Randeva HS. Metformin treatment may increase omentin-1 levels in women with polycystic ovary syndrome. Diabetes. 2010;59(12):3023-31.

11. Zhou L, He W, Wang W, Zhou D. Altered circulating levels of adipokine omentin-1 in patients with prostate cancer. OncoTargets Ther. 2019;12:3313-9.

12. Zhang YY, Zhou LM. Omentin-1, a new adipokine, promotes apoptosis through regulating Sirt1-dependent p53 deacetylation in hepatocellular carcinoma cells. Eur J Pharmacol. 2013;698(1-3):137-44.

13. Souza Batista CM, Yang RZ, Lee MJ, Glynn NM, Yu DZ, Pray J, Ndubuizu K, et al. Omentin plasma levels and gene expression are decreased in obesity. Diabetes. 2007;56(6):1655-61.

14. Moreno-Navarrete JM, Catalán V, Ortega F, Gómez-Ambrosi J, Ricart W, Frühbeck $G$, et al. Circulating omentin concentration increases after weight loss. Nutr Metab (Lond). 2010;7:27.

15. Pan HY, Guo L, Li Q. Changes of serum omentin-1 levels in normal subjects and in patients with impaired glucose regulation and with newly diagnosed and untreated type 2 diabetes. Diabetes Res Clin Pract. 2010;88(1):29-33.

16. Tan BK, Adya R, Farhatullah S, Lewandowski KC, O'Hare P, Lehnert $H$, et al. Omentin-1, a novel adipokine, is decreased in overweight insulin-resistant women with polycystic ovary syndrome: ex vivo and in vivo regulation of omentin- 1 by insulin and glucose. Diabetes. 2008;57(4):801-8.

17. Aktas G, Alcelik A, Ozlu T, Tosun M, Tekce BK, Savli H, et al. Association between omentin levels and insulin resistance in pregnancy. Exp Clin Endocrinol Diabetes. 2014;122(3):163-6.

18. Tekce H, Tekce BK, Aktas G, Alcelik A, Sengul E. Serum omentin-1 levels in diabetic and nondiabetic patients with chronic kidney disease. Exp Clin Endocrinol Diabetes. 2014;122(8):451-6. 